This article was downloaded by: [Max Planck Inst \& Research Groups Consortium]

On: 16 October 2009

Access details: Access Details: [subscription number 789998259]

Publisher Psychology Press

Informa Ltd Registered in England and Wales Registered Number: 1072954 Registered office: Mortimer House, 37-41 Mortimer Street, London W1T 3JH, UK

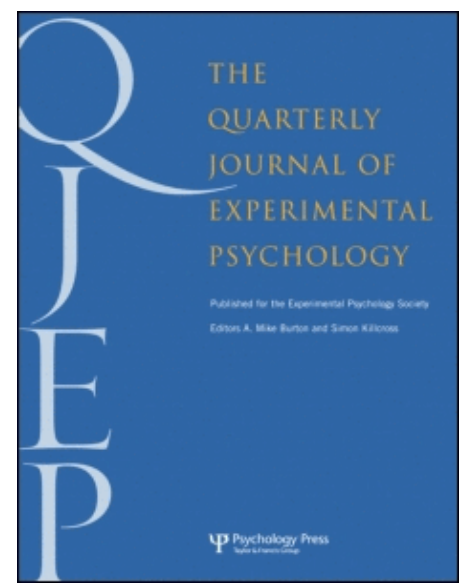

The Quarterly Journal of Experimental Psychology

Publication details, including instructions for authors and subscription information:

http://www.informaworld.com/smpp/title content=t716100704

\title{
Speech planning during multiple-object naming: Effects of ageing
}

Linda Mortensen a; Antje S. Meyer ${ }^{\text {b; }}$ Glyn W. Humphreys ${ }^{\mathrm{b}}$

a Rice University, Houston, TX, USA ${ }^{\mathrm{b}}$ Behavioural Brain Sciences Centre, University of Birmingham, Birmingham, UK

First Published on: 09 August 2007

To cite this Article Mortensen, Linda, Meyer, Antje S. and Humphreys, Glyn W.(2007)'Speech planning during multiple-object naming: Effects of ageing',The Quarterly Journal of Experimental Psychology,61:8,1217 - 1238

To link to this Article: DOI: $10.1080 / 17470210701467912$

URL: http://dx.doi.org/10.1080/17470210701467912

\section{PLEASE SCROLL DOWN FOR ARTICLE}

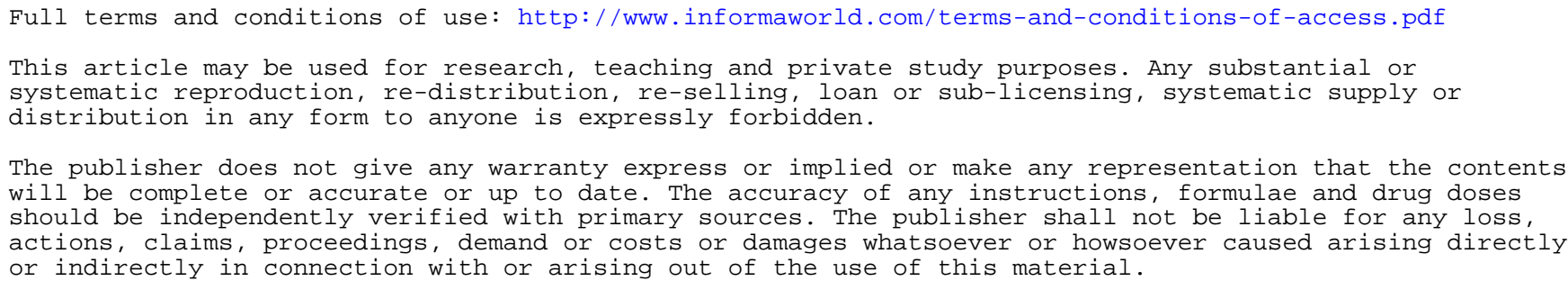

The publisher does not give any warranty express or implied or make any representation that the contents will be complete or accurate or up to date. The accuracy of any instructions, formulae and drug doses should be independently verified with primary sources. The publisher shall not be liable for any loss, actions, claims, proceedings, demand or costs or damages whatsoever or howsoever caused arising directly or indirectly in connection with or arising out of the use of this material. 


\title{
Speech planning during multiple-object naming: Effects of ageing
}

\author{
Linda Mortensen \\ Rice University, Houston, TX, USA \\ Antje S. Meyer and Glyn W. Humphreys \\ Behavioural Brain Sciences Centre, University of Birmingham, Birmingham, UK
}

\begin{abstract}
Two experiments were conducted with younger and older speakers. In Experiment 1, participants named single objects that were intact or visually degraded, while hearing distractor words that were phonologically related or unrelated to the object name. In both younger and older participants naming latencies were shorter for intact than for degraded objects and shorter when related than when unrelated distractors were presented. In Experiment 2, the single objects were replaced by object triplets, with the distractors being phonologically related to the first object's name. Naming latencies and gaze durations for the first object showed degradation and relatedness effects that were similar to those in single-object naming. Older participants were slower than younger participants when naming single objects and slower and less fluent on the second but not the first object when naming object triplets. The results of these experiments indicate that both younger and older speakers plan object names sequentially, but that older speakers use this planning strategy less efficiently.
\end{abstract}

A central assumption in theories of speech production is that words are planned in essentially the same way when they are uttered in isolation as in a sentence context. However, when speakers generate multiword utterances, they must engage in more extensive speech planning than when they produce single words. Among other things, they must coordinate the planning processes of successive words with each other (Levelt \& Meyer, 2000). The present study examined how this is achieved by younger and older speakers. We focused on simple utterances such as "bag, cake, sun", in which speakers name several objects in noun phrases. Below, we review the evidence about how speakers plan such utterances, focusing first on young speakers and then on differences between younger and older speakers.

\section{Production of multiword utterances}

\section{Speech planning at utterance initiation}

Before initiating an utterance, speakers engage in several levels of speech planning. They first think about what to say. Based on the resulting prelinguistic representation, they select lexical items from the mental lexicon and subsequently generate

Correspondence should be addressed to Linda Mortensen, Department of Psychology, University of Copenhagen, Linnésgade 22, DK-1361 Copenhagen K, Denmark. E-mail: linda.mortensen@psy.ku.dk

We thank Zenzi Griffin and an anonymous reviewer for helpful comments on an earlier version of this paper. 
the corresponding morphological and phonological plans. Based on the phonological representation, a phonetic plan is generated and executed (e.g., Dell, 1986; Garrett, 1975; Levelt, 1989; Levelt, Roelofs, \& Meyer, 1999).

All current theories of speech planning assume that speakers generate utterances that include more than one or two words incrementally. This means that they plan a fragment of their utterance, begin to speak, and plan the next fragment while they are producing the first fragment. Analyses of speech errors have shown that the span of utterance planning is wider at early than at later planning levels. For instance, word exchanges, such as "watch the radio and listen to TV", which occur during lexical selection, often involve nonadjacent words belonging to different phrases, whereas sound exchanges, such as "children interfere with your nife lite” (Garrett, 1975, pp. 155 and 141), which arise during phonological encoding, typically involve adjacent words appearing in the same phrase.

Studies of speech onset latencies provide further evidence for this variation in planning spans. For instance, Smith and Wheeldon (1999) showed that when speakers described objects in sentences beginning with a noun phrase, latencies were longer when the initial phrase was conjoined (e.g., "the dog and the foot move above the kite") than when it was simple ("the dog moves above the foot and the kite"), although the two sentence types were equally complex overall. The authors concluded that before utterance onset, lexical selection was only completed for the first phrase. This conclusion was supported by the finding that the effect of initial phrase complexity was reduced when speakers viewed the objects, and presumably selected their names, before producing the sentences.

Other studies of sentence planning have used versions of the picture-word interference paradigm, wherein speakers name or describe objects accompanied by related or unrelated distractor words. For instance, Meyer (1996) asked native speakers of Dutch to name pairs of objects in conjoined noun phrases or sentences, such as (the Dutch equivalent of) "the arrow and the bag" or "the arrow is next to the bag". Auditory distractors that were semantically related to the first or second noun delayed the utterance onset relative to unrelated distractors, indicating that both nouns were selected before utterance onset. Distractors that were phonologically related to the first noun had a facilitatory effect on the utterance onset latencies, whereas distractors that were phonologically related to the second noun had an inhibitory effect. Meyer suggested that only the form of the first noun was selected before utterance onset, but that the form of the second noun was activated to some extent (see also Jescheniak, Schriefers, \& Hantsch, 2003b). The difference in the results obtained for semantic and phonological distractors is consistent with the assumption of a larger planning span at the lexical than the phonological level. In a subsequent study, Meyer (1997) replicated the inhibitory effect of semantic relatedness for the first noun but failed to reproduce the effect for the second noun, suggesting that the participants for some reason selected a smaller planning unit than that in the earlier study. Apparently speakers have some flexibility in their choice of planning units (see also Schriefers \& Teruel, 1999).

Other picture-word interference studies have investigated the production of adjective-noun phrases, such as "the red chair". With this type of phrase, distractors that are semantically related to the noun tend to have an inhibitory effect on utterance latencies (Schriefers, 1992, 1993). The effect of distractors that are phonologically related to the noun appears to be more variable and might depend on the number of preceding words (e.g., Costa \& Caramazza, 2002; Miozzo \& Caramazza, 1999). For instance, in a study involving German speakers, Jescheniak et al. (2003b) found that phonologically related distractors facilitated the production of bare noun and determiner-noun phrases-for example, “(der) Hund"-(the) dog-but delayed the onset of complex adjective-noun phrases-for example, "der grosse rote Hund"-the big red dog.

In summary, speakers plan their utterances further ahead at early than at later levels of speech production. Before utterance onset, they normally generate a prelinguistic representation 
of the entire clause but select the words for only the first phrase (e.g., Meyer, 1996; Smith \& Wheeldon, 1999) and complete the phonological forms of only a few words (e.g., Costa \& Caramazza, 2002; Wheeldon \& Lahiri, 1997). Speakers are flexible, however, in their planning at the lexical level, as demonstrated by the contrasting results of the studies by Meyer (1996, 1997), and at the phonological level, as demonstrated by the contrasting results of Costa and Caramazza (2002) and Jescheniak et al. (2003b).

\section{Speech planning during utterance generation}

The above studies concerned how extensively the words of an utterance are planned before utterance onset. However, most relevant to the present research are studies of how the planning processes for these words are coordinated with each other. Smith and Wheeldon (2004) showed participants displays featuring a target object (e.g., a dog) with a distractor word (e.g., "doll") to its right. Participants had to describe the displays in sentences that placed the target and distractor in the same phrase (e.g., "the dog and the doll move down") or in different phrases ("the dog moves towards the doll"). For both sentence types, speech onset latencies were longer in a semantically related than in an unrelated condition. Phonologically related distractors yielded a facilitatory effect, but only when the target and distractor occurred in the same phrase. Smith and Wheeldon concluded that words were planned in parallel at both the lexical and phonological level but that the span of parallel planning was wider at the lexical level.

In contrast to the above data, eye-tracking studies provide evidence for sequential planning of object names. When speakers name several objects, they virtually always look at each of them in the order of mention. Their eye gaze tends to run slightly ahead of their overt speech: They typically look at the first object for about $600 \mathrm{~ms}$ to $800 \mathrm{~ms}$, then shift their gaze to the next object, and shortly afterwards say the name of the first object (for reviews see Griffin, 2004; Meyer \& Lethaus, 2004; see also Griffin \& Bock, 2000). A robust finding is that the gaze duration for an object (defined as the time between the beginning of the first and the end of the last fixation on the object) depends on the total time required to identify the object, select its name, and retrieve the corresponding word form. Thus, when objects are difficult to identify, appropriate names difficult to find, or the word forms difficult to generate, speakers look longer at the objects than when these processes are easier (see Griffin, 2004; Griffin \& Oppenheimer, 2006; Meyer \& Lethaus, 2004; Meyer, Roelofs, \& Levelt, 2003; van der Meulen, Meyer, \& Levelt, 2001). For instance, Meyer, Sleiderink, and Levelt (1998) asked participants to name object pairs in conjoined noun phrases, such as "scooter and hat". The gaze duration for the first object was shorter when it had a high-frequency than a low-frequency name. Meyer et al. concluded that the speakers' gaze remained on the first object until its name had been planned to the level of phonological form. Only then did participants shift their gaze to the next object. Similarly, Griffin (2001) asked participants to describe triplets of objects in sentences such as "the star and the screw are above the glass". She varied the name agreement and frequency of the second and third object names. Paralleling the results obtained by Meyer et al., this affected how long these objects were looked at.

In Griffin's (2001) study, the properties of the second and third objects did not affect utterance onset latencies, demonstrating that the speakers did not select the names of these objects before utterance onset. Nevertheless, in this study, and all other multiple-object naming studies using eye tracking, the speakers typically began to inspect the second object before utterance onset and presumably began to process it. Griffin (2003) varied the length of the name of the first of two objects that participants had to name. This did not affect the gaze durations for the first object, but it did affect how much time speakers spent looking at the second before utterance onset: The second object was gazed at for longer when the first one had a short name than when it had a long name. Griffin proposed that the speakers had access to information about the length of the 
words that they were about to say and that they used this information to decide how much time before utterance onset they needed to spend planning the second word in order to produce the utterance fluently (for an alternative account, see Meyer, Belke, Häcker, \& Mortensen, 2007). In line with this proposal, she found that a group of speakers who articulated the object names quite slowly spent less time before speech onset looking at the second object than a group who spoke faster. She proposed that this pattern arose because the slower speakers had more time than the faster speakers to prepare the second object name during the articulation of the first object name and could therefore afford to spend less time looking at the second object before speech onset.

In summary, the results of the eye-tracking studies show that young speakers inspect the objects that they name in a highly sequential fashion, and that their eye gaze only moves from one object to the next when they have identified the first object and have retrieved the phonological form of its name. Given the strong link between eye gaze and visual attention (e.g., Irwin, 2004), this means that speakers focus their attention on the objects that they name in a highly sequential fashion. However, in typical multiple-object naming experiments, speakers can often identify objects extrafoveally, and Morgan and Meyer (2005) showed that object names could become activated before the objects were fixated upon. Therefore, there can be some temporal overlap in the processing of successive objects and in the retrieval of their names. Nevertheless, the key finding from the eye-tracking studies involving young speakers is that they focus on the objects in a highly sequential manner, and that their eye movements are tightly time-locked to their speech, with the eyes always running slightly ahead of the overt speech.

\section{Ageing and the production of multiword utterances}

There is both anecdotal and experimental evidence that older speakers speak more slowly and less fluently than younger speakers (e.g., Bortfeld, Leon, Bloom, Schober, \& Brennan, 2001; Cooper, 1990). However, it is not clear why they do this. Older speakers experience lexical retrieval failures, leading to tip-of-the-tongue states, more often than younger speakers, but in speeded naming tasks they are not consistently slower than younger speakers (for recent reviews see Belke \& Meyer, in press; Mortensen, Meyer, \& Humphreys, 2006). Thus, their slower connected speech cannot be directly related to the speed of lexical retrieval processes. Though syntactic processing has not been extensively studied, older speakers appear to be as efficient as younger speakers at generating the syntactic structure of utterances (Davidson, Zacks, \& Ferreira, 2003). Thus, their slower and more disfluent speech does not seem to be due to a syntactic encoding deficit.

Age-related differences in speech rate and fluency might be due to the way older and younger speakers coordinate the planning processes for successive words of an utterance with each other. In a multiple-object naming task, slow and hesitant speech could, for instance, arise if older speakers did not begin to inspect a new object slightly before initiating the name of the preceding object, as young speakers do, but turned to a new object only after they had produced the preceding object name. So far, only a few studies have examined in detail how older speakers plan multiword utterances. Griffin and Spieler (2000) asked young and older participants to say "they saw the ..." and to complete the sentence with the name of a pictured object. The objects varied in name agreement and name frequency. When the task was performed without time pressure, the utterance onset latencies of both groups of participants were longer for objects with medium than high name agreement and longer for objects with low-frequency than high-frequency names. This indicates that the object name was planned before utterance onset. In contrast, when the task was performed under time pressure, young participants showed effects of name agreement and name frequency on their 
utterance durations and fluency, ${ }^{1}$ whereas older participants continued to show effects on their utterance latencies. Griffin and Spieler concluded that the older participants were more likely than the younger participants to plan the object name before utterance onset. The older participants began to speak later but spoke as fluently as the young participants, probably because they planned the object name before utterance onset.

In Griffin and Spieler's (2000) study, the older speakers showed a wider planning span than the younger speakers. However, in other eye-tracking studies, Griffin (2001) and Spieler and Griffin (2006; see also Griffin \& Spieler, 2006) did not find any evidence that older speakers planned their utterances more thoroughly before speech onset than did younger speakers. Spieler and Griffin (2006) asked older speakers to carry out the same task as the younger speakers in Griffin's (2001) study (i.e., to describe objects in sentences such as "the star and the screw are above the glass"). Replicating the findings obtained for the younger speakers, the older speakers' naming latencies were unaffected by the properties of the second and third objects, demonstrating that they were not more likely to plan the names of these objects before speech onset than were the younger speakers. However, the older speakers needed more time to plan the names, as indicated by their long gaze durations and by disfluencies before difficult names. Similarly, Martin, Miller, and $\mathrm{Vu}$ (2004) found no evidence for age differences in utterance planning: On the moving pictures task (Smith \& Wheeldon, 1999), both young and older participants showed effects of initial phrase complexity on utterance latencies, demonstrating that the initial phrase was planned before utterance onset in both age groups.

In summary, the existing studies do not suggest that older speakers differ consistently from younger speakers in their advance planning span, though there is some indication, from Griffin and Spieler's (2000) study, that they sometimes plan their utterances further ahead than do younger speakers.

\section{The present study}

The main aim of the present study was to examine further whether younger and older speakers differed in the way they plan descriptive noun phrases such as "bell, toe, rope". However, we first needed to establish whether they differed in the planning of single object names. In Experiment 1, participants saw pictures of single objects in intact and visually degraded versions while hearing distractor words that were phonologically related or unrelated to the target name. Visual degradation should delay object identification (e.g., Biederman, 1987; Biederman \& Cooper, 1991; Meyer et al., 1998), whereas the related distractors should facilitate the phonological encoding of the object name, compared with the unrelated distractors (e.g., Damian \& Martin, 1999; Meyer \& Schriefers, 1991; Wilshire \& Saffran, 2005). One goal of this experiment was to establish that visual degradation and phonological relatedness indeed affected the naming latencies. A second goal was to determine whether younger and older speakers differed in when they began to encode the name of an object. If identification of the object is completed when phonological encoding of its name begins, the effects of visual degradation and phonological relatedness should be additive. In contrast, if the two processing steps overlap, the effects might interact with each other.

In Experiment 2, participants saw pictures of object triplets. All three objects were intact or degraded. Auditory distractors were presented, which were phonologically related or unrelated to the name of the object that was to be named first. We aimed to determine whether younger and older speakers differed in how far they had planned the name of an object when they shifted their gaze to the next object. We know from

\footnotetext{
${ }^{1}$ In this and the following study by Griffin and Spieler (2000, 2006), a word was considered disfluent when it was preceded by a silent pause (over $200 \mathrm{~ms}$ ), a filled pause ("um" or "uh"), a false start ("the gira- zebra"), a stressed article ("thee"), or when it was corrected ("the giraffe, zebra").
} 
earlier studies that young speakers look at objects they name until they have encoded the phonological form of its name and then shift their gaze to the next object (e.g., Meyer et al., 1998). Therefore, they should look longer at the first object when it is degraded than when it is intact and when a phonologically unrelated than when a related distractor is present. If older speakers use the same strategy, their gaze durations should show the same effects. The use of this strategy would minimize the processing load but might lead to slow and hesitant speech. We call this hypothesis the minimal load hypothesis. Alternatively, older speakers could shift their gaze earlier than younger speakers. Although this might increase the task difficulty because the processing of the two objects would overlap more in time, it would increase the time available to plan the second object name and thus the likelihood of maintaining fluency. We call this the fluency maintenance hypothesis. If speakers initiate the eye movement to the second object as soon as the first object has been recognized, there should be an effect of degradation but no effect of phonological relatedness on the duration of the gazes to the first object.

We were primarily interested in the speakers' coordination of the onset of their speech with the shift of gaze from the first to the second object. We presented object triplets, rather than object pairs, because we also wanted to explore how the speakers would coordinate their speech and gaze after speech onset. Would the older speakers be less fluent than the younger speakers and would this be mirrored in the durations of their gazes to the objects?

\section{EXPERIMENT 1: SINGLE-OBJECT NAMING}

\section{Method}

\section{Participants}

In both experiments, the young participants were students of the University of Birmingham. The older participants were recruited from a participant pool at the School of Psychology, University of Birmingham. All participants were native speakers of English and had normal or corrected-to-normal vision and normal hearing. The young participants received course credits for participating, and the older participants received payment. In Experiment 1, 20 young participants between 18 and 21 years of age (mean $=19.3$ years, $S D=$ 1.1) were tested. A total of 18 older participants were tested. Two of them had difficulty hearing the distractor words, and their responses were therefore excluded from the analyses. The remaining 16 older participants were between 63 and 88 years of age $($ mean $=72.6$ years, $S D=7.3$ ). Information about years of education was not obtained for the participants in this experiment.

\section{Materials}

We used black-and-white line drawings of objects selected from a picture database provided by the Max Planck Institute for Psycholinguistics (Nijmegen, The Netherlands). In Experiment 1, we used 55 objects. The objects fitted frames of $10 \mathrm{~cm}$ by $10 \mathrm{~cm}$, corresponding to $9.5^{\circ}$ by $9.5^{\circ}$ of visual angle when viewed from the participant's position. Each object was shown in an intact and a visually degraded version. The degradation was created by deleting stripes of pixels from the intact drawings. Approximately 50\% of the pixels were deleted. The target names were between one and three syllables in length. Each target object was paired with two auditory distractor words. One was phonologically related to the target, and the other was unrelated. The related distractor shared the final segments, minimally the final vowel and consonant, with the target. On average, 2.49 segments were shared. The mean number of segments in the target and related distractor was the same $(3.96, S D=1.14$, and $3.93, S D=1.09$, respectively). The targets and distractors were recombined to form semantically and phonologically unrelated pairs. The unrelated distractor never shared the final vowel and consonant with the target. The presentation of the distractors was timed such that the onset of the first vowel that the distractor shared with the target coincided with the picture 
onset (Meyer \& Schriefers, 1991). This yielded an average stimulus onset asynchrony (SOA) of $207 \mathrm{~ms}(S D=113)$. The distractor words were recorded and digitized using a Kay $4300 \mathrm{~b}$ Computerised Speech Lab (CSL). They were spoken by a female native speaker of English. The materials are listed in the Appendix.

\section{Design}

The design included two factors, each with two levels: visual degradation (intact or degraded target) and phonological relatedness (related or unrelated distractor). Four experimental blocks of 55 target-distractor pairs were presented. In two successive blocks the target objects appeared in the intact version, and in the following or preceding two blocks they appeared in the degraded version. Within each block each target appeared once, and half of the targets were combined with related and half with unrelated distractors. The order of presenting the intact and degraded blocks was counterbalanced across participants. The order of presenting the targets within a block was random and different for each participant. In addition to the experimental blocks, there were two practice blocks in which all targets appeared without a distractor. In one practice block the pictures appeared in the intact version, and in the other block they appeared in the degraded version. These practice blocks preceded the corresponding experimental blocks.

\section{Apparatus}

In both experiments, we used the Nijmegen Experiment Set-Up (NESU) software (Max Planck Institute for Psycholinguistics, 2000) to control the stimulus presentation and record speech onset latencies. In Experiment 1, the pictures were displayed on a 15-inch Iiyama monitor. The distractors were played through Beyerdynamic headphones. The participants' speech was recorded using a Sennheiser microphone and a Sony digital audiotape recorder.

\section{Procedure}

Participants were tested individually in a soundattenuated booth where they were seated approximately $60 \mathrm{~cm}$ in front of a monitor. They were told that they would see objects, some of which would be complete and some incomplete. They were instructed to name the objects using bare nouns. At the same time, they would hear words, which they should try to ignore. Speed and accuracy were given equal emphasis. The instructions did not include any spoken or written examples. Before each set of blocks (intact or degraded), the participants received a picture booklet that displayed each object with its name printed underneath. The booklet showed the objects in their intact or degraded version depending on the blocks to follow. When the participants had familiarized themselves with the objects and their names, they received a second booklet displaying the objects without their names and were asked to name them. Any naming errors were corrected. Then the first set of practice and experimental blocks were presented. In the practice block, the objects were presented without the distractor words. Any errors occurring during the practice block were corrected. At the beginning of each experimental trial, a fixation mark appeared in the centre of the screen for $500 \mathrm{~ms}$, after which an object was presented for $1,500 \mathrm{~ms}$, accompanied by an auditory distractor word. A blank interval of $900 \mathrm{~ms}$ followed, and the next trial began. All responses were recorded. Any incorrect or disfluent responses and any cases where the voice key was triggered by environmental noise were noted by the experimenter. The same procedure was used with young and older participants, except that for each of the older adults the volume at which the distractors were played was set to a comfortable level. Additionally, the older participants heard the distractors again after the end of the experiment and were asked to repeat them. All participants repeated all the words correctly.

\section{Results and discussion}

Responses were considered errors if the object name was incorrect, corrected, preceded by a filled pause ("um" or "uh") or by a determiner, or the naming latency exceeded $1,500 \mathrm{~ms}(4.3 \%$ and $7.6 \%$ of all 
Table 1. Young and older participants' mean error rates and mean naming latencies in Experiment 1

\begin{tabular}{lccccc}
\hline & \multicolumn{2}{c}{ Error rate } & & \multicolumn{2}{c}{ Naming latency } \\
\cline { 2 - 3 } \cline { 6 - 6 } Condition & Young & Older & & Young & Older \\
\hline Intact & & & & \\
$\quad$ Unrelated & 4.5 & 5.6 & $750(27)$ & $830(30)$ \\
$\quad$ Related & 3.5 & 2.9 & $721(25)$ & $776(28)$ \\
$\quad$ Relatedness effect & 1.0 & 2.7 & 29 & 54 \\
Degraded & & & & \\
$\quad$ Unrelated & 5.6 & 12.8 & $821(30)$ & $934(34)$ \\
$\quad$ Related & 3.8 & 9.4 & $775(29)$ & $893(32)$ \\
$\quad$ Relatedness effect & 1.8 & 3.4 & & 46 & 41 \\
$\quad$ Degradation effect & 0.7 & 6.9 & 63 & 111 \\
\hline
\end{tabular}

Note: Error rates in percentages; naming latencies in ms. Standard errors are given in parentheses.

trials for young and older participants, respectively). All error trials were excluded from the latency analysis. Trials on which the voice key mistriggered (7.3\% and $6.6 \%$ of all trials) or the naming latency deviated by more than three standard deviations from a participant's condition mean $(1.0 \%$ and $1.1 \%$ of correct trials) were also excluded.

Mean error rates and mean naming latencies were entered into analyses of variance with age group as a between-participants variable and visual degradation and phonological relatedness as within-items and within-participants variables. We only report the participant means but report the results of the analyses based on participant means $\left(F_{1}\right)$ and item means $\left(F_{2}\right)$. Table 1 shows the results.

\section{Error rates}

The older participants made slightly more errors than the young participants (means: $7.6 \%$ vs. $4.3 \%) ; F_{1}(1,34)=3.75, p<.07 ; F_{2}(1,108)=$ $11.46, p=.001$. This difference in overall error rate arose because the older participants produced the object name too late (i.e., later than $1,500 \mathrm{~ms}$ after picture onset) more often than did the young participants $(4.9 \%$ vs. $1.4 \%)$. Both age groups very rarely used an incorrect name (1.1\% vs. $1.0 \%)$, or corrected a name or added a pause or a determiner $(1.7 \%$ vs. $1.8 \%)$.

The effect of degradation was significant, with more errors occurring in the degraded condition (means: $7.9 \%$ vs. $4.1 \%) ; F_{1}(1,34)=9.82, p<$ $.01 ; F_{2}(1,108)=32.51, p<.001$. This effect was larger in older than in young participants $(6.9 \%$ vs. $0.7 \%)$, yielding a significant interaction between age group and degradation, $F_{1}(1,34)=$ 6.51, $p<.05 ; F_{2}(1,108)=23.67, p<.001$. Within-group analyses showed that the degradation effect was significant in older participants, $F_{1}(1,15)=7.94, p<.05 ; F_{2}(1,54)=33.04$, $p<.001$, but not in young participants, $F_{\mathrm{s}}<$ 1.20. The effect of relatedness was significant, with fewer errors occurring in the related condition $(4.9 \%$ vs. $7.1 \%) ; F_{1}(1,34)=8.58, p<.01 ; F_{2}(1$, $108)=19.28, p<.001$. There was no interaction between degradation and relatedness and no interaction of these two variables with age group. ${ }^{2}$

\section{Naming latencies}

Naming latency was measured from picture onset. There was a significant effect of age group, with older participants being slower than young participants to name the objects (means: $858 \mathrm{~ms}$ vs. $767 \mathrm{~ms}) ; F_{1}(1,34)=5.29, p<.05 ; F_{2}(1,108)=$ $47.89, p<.001$, and a significant effect of degradation, with longer latencies in the degraded condition (856 ms vs. $770 \mathrm{~ms}) ; F_{1}(1,34)=51.07$; $F_{2}(1,108)=286.76$, both $p s<.001$. This effect was larger in older than in young participants (110 $\mathrm{ms}$ vs. $63 \mathrm{~ms})$, yielding an interaction between age group and degradation that approached significance, $F_{1}(1,34)=3.85, p<$ $.06 ; F_{2}(1,108)=15.86, p<.001$. The effect of relatedness was significant, with shorter latencies in the related condition (791 ms vs. $834 \mathrm{~ms}$ ); $F_{1}(1,34)=77.61 ; F_{2}(1,108)=65.07$, both $p s<.001$, and was similar in size for young and older participants ( $38 \mathrm{~ms}$ vs. $48 \mathrm{~ms}$ ). The effect of relatedness was larger in the degraded

\footnotetext{
${ }^{2}$ Analyses of the error rates in Experiment 1 and of the error and pause rates in Experiment 2 were also performed on the arc-sine transformed data. These analyses yielded the same results as the reported analyses.
} 
condition than in the intact condition for the young participants ( $46 \mathrm{~ms}$ vs. $29 \mathrm{~ms}$ ), but was smaller in the degraded condition for the older participants (41 ms vs. $54 \mathrm{~ms}$ ). However, the three-way interaction between age group, degradation, and relatedness was only marginally significant, $F_{1}(1,34)=4.54, p<.05 ; F_{2}(1,108)=$ $3.09, p<.10$. Furthermore, within-group analyses showed that the interaction between degradation and relatedness was not significant for the young or older participants.

As expected, the participants' naming latencies were affected by visual degradation and phonological relatedness. There was no significant interaction between these effects for either group of participants. This result suggests that when naming pictures of single objects, speakers identify an object before they phonologically encode its name, consistent with serial stage models of object naming (e.g., Levelt et al., 1999). The older participants named the objects more slowly than did the young participants, particularly when the objects were degraded. This finding is consistent with those of earlier studies in which older adults were slower and made more errors than younger adults on tasks in which visually incomplete stimuli were used (Danziger \& Salthouse, 1978; Frazer \& Hoyer, 1992; Salthouse \& Prill, 1988; Whitfield \& Elias, 1992).

In contrast, the older participants showed a phonological relatedness effect of the same size as that for the young participants. This result replicates findings of Taylor and Burke (2002) and suggests that the activation of the phonological forms of words is unaffected by ageing. If the overall slower naming in older than young participants was due to slow activation of the phonological forms of the target names, either of the form as a whole or of the end segments that were shared between the target and the related distractor, one might have expected that the older participants had benefited more than the young participants from hearing a related distractor and, consequently, had shown a larger relatedness effect.

\section{EXPERIMENT 2: MULTIPLE-OBJECT NAMING}

Experiment 2 examined whether older speakers differed from younger speakers in how they planned the names of several objects and in how they coordinated their speech planning with their eye gaze. At trial onset, participants viewed three intact or three visually degraded objects arranged to form an inverse triangle. They were asked to name them in the order left, right, and bottom object. While naming the objects, they heard a distractor word, which they had to ignore. The participants' speech and eye movements were recorded.

\section{Method}

\section{Participants}

A total of 15 older participants between 59 and 80 years of age (mean $=68.0$ years, $S D=6.4$ ) were tested. The results were compared to those obtained from 16 young participants between 18 and 26 years of age (mean $=20.3$ years, $S D=$ 1.9). Part of the results obtained from the young participants is reported in an earlier study (Meyer et al., 2007). ${ }^{3}$ The mean years of education were similar for the young $(13.7, S D=1.2)$ and the older $(14.4, S D=3.8)$ participants.

\section{Materials}

The 55 target-distractor pairs used in Experiment 1 were also used in Experiment 2. 110 objects were combined with the target objects to form object triplets each featuring a left object (the target), a right and a bottom object.

The objects of a triplet were either all intact or all visually degraded. Their names were unrelated in meaning (i.e., the objects did not come from the

\footnotetext{
${ }^{3}$ In Experiment 3 of Meyer et al. (2007), we only reported the young participants' utterance latencies and left-object gaze durations. We did not report the measures for the right object (i.e., naming latencies and gaze durations) or the speech duration and pause measures reported here. In the present paper, we offer an in-depth examination of how speakers plan their speech during a multiple-object naming task and of how older speakers differ from young speakers in their speech planning.
} 
same semantic category) and form (i.e., they did not share more than one segment in corresponding word positions), and the names of the right and bottom objects were unrelated in meaning and form to the distractor words. (One exception was the object toaster which was end-related to the distractor word hooter). The names of the right and bottom objects were between one syllable and three syllables in length. In all but three of the triplets, the target name and the name of the right object were matched on number of syllables. The objects fitted frames of $7 \mathrm{~cm}$ by $7 \mathrm{~cm}\left(6.7^{\circ}\right.$ by $\left.6.7^{\circ}\right)$. The midpoint-to-midpoint distance between the left and right object was $19 \mathrm{~cm}\left(18^{\circ}\right)$, and between the left and bottom object and the right and bottom object it was $15 \mathrm{~cm}\left(14^{\circ}\right)$.

\section{Design}

The design was the same as that in Experiment 1, except that objects were replaced with object triplets. Additionally, in each experimental block, four practice trials preceded the experimental trials.

\section{Apparatus}

The pictures were displayed on a 19-inch Samtron 95P Plus colour monitor. The distractor words were played through Sony earphones or Beyerdynamic headphones. The participants' speech was recorded with a Sennheiser microphone that was connected to a computer on which audio-recording software was installed. The recordings were used to determine utterance onset latencies and naming latencies for the right objects. Eye movements were monitored with an SMI EyeLink 2D head-mounted eye-tracking system, which estimates the position of both eyes every $4 \mathrm{~ms}$ with an accuracy of about $0.5^{\circ}$ of visual angle.

\section{Procedure}

The procedure was as that in Experiment 1 except for the following changes. Participants were told they would see triplets of objects. They were instructed to name the objects in a left-rightbottom order using bare nouns. Before the beginning of the experimental blocks, they put on the ear- or headphones and the headband of the eyetracker, and the eye-tracking system was calibrated. At the beginning of each experimental block, a central fixation mark appeared, which participants were instructed to look at. This allowed an automatic drift correction in the calibration. At the beginning of each experimental trial, a fixation mark appeared in the centre of the top-left quadrant of the screen for $500 \mathrm{~ms}$, after which an object triplet appeared for 4,000 ms, accompanied by an auditory distractor word. A blank interval of 900 ms followed, and the next trial began.

Analysis of eye movements. The EyeLink software determines the average position and duration of fixations between successive saccades. A saccade was defined as an eye movement covering a minimum of $0.15^{\circ}$ of visual angle at a minimum velocity of $30^{\circ} \mathrm{s}$ with an acceleration of minimally $8,000^{\circ} / \mathrm{s}^{2}$. We categorized a fixation as being on an object when it fell within a virtual frame of $7 \mathrm{~cm}$ by $7 \mathrm{~cm}\left(6.7^{\circ}\right.$ by $\left.6.7^{\circ}\right)$ enclosing the object. Participants were instructed to look at the fixation mark at the beginning of each trial. Sometimes the first fixation of a trial was located slightly below or to the left or right of the fixation mark. We corrected for such drifts by manually aligning the first fixation with the fixation mark. The positions of the remaining fixations of the trial were recomputed accordingly. We analysed first-pass gaze durations (gaze durations hereafter). The gaze duration for a region of interest was computed by subtracting the onset of the first from the offset of the last successive fixation on the region before the shift of gaze to a location outside the region.

Utterance onset latencies and naming onset latencies for the right object were measured relative to the onset of the first fixation on the left and right object, respectively. ${ }^{4}$

\footnotetext{
${ }^{4}$ The results for the naming latencies for the right object were identical to those for the gaze durations for the right object. We therefore only report the results for the latter measure.
} 


\section{Results and discussion}

Responses were considered errors if one or more names were incorrect, corrected, preceded by filled pauses, by determiners, or by the conjunction "and", or if the utterance was repaired or the utterance latency exceeded $4,000 \mathrm{~ms}$ (3.9\% and $9.7 \%$ of all trials for young and older participants, respectively). All error trials were excluded from the latency and gaze duration analyses. Trials on which silent pauses (i.e., $200 \mathrm{~ms}$ or longer) occurred between the names were identified, but were not considered an error. Trials on which the utterance onset latency deviated by more than three standard deviations from a participant's condition mean $(0.9 \%$ of correct trials for both young and older participants) and those on which participants did not fixate on all objects and in the expected order $(7.3 \%$ and $10.2 \%$ of all trials) were also excluded.

Table 2 shows young and older participants' mean error rates, mean utterance onset latencies, and mean left-object gaze durations.

\section{Error rates}

The older participants made significantly more errors than the young participants overall (means: $9.7 \%$ vs. $3.9 \%) ; F_{1}(1,29)=10.58, p<.01 ; F_{2}(1$, $108)=42.72, p<.001$, as well as when errors were categorized as pertaining to the left object (i.e., left-object names that were incorrect, corrected, or preceded by a filled pause or a determiner; $3.6 \%$ vs. $1.4 \%) ; F_{1}(1,29)=9.45$, $F_{2}(1,108)=10.22$, both $p s<.01$, or the right object (i.e., right-object names that were incorrect, corrected, or preceded by a filled pause, a determiner, or by "and"; $3.6 \%$ vs. $1.4 \%) ; F_{1}(1,29)=8.47$, $p<.01 ; F_{2}(1,108)=15.42, p<.001$. As in Experiment 1, the age difference in the use of incorrect names was small (2.2\% vs. $1.0 \%)$.

The effect of degradation was significant, with more errors occurring in the degraded condition (means: $8.7 \%$ vs. $4.9 \%) ; F_{1}(1,29)=10.63, p<$ $.01 ; F_{2}(1,108)=24.44, p<.001$. This effect was larger in older than in young participants (6.7\% vs. $1.1 \%)$, yielding a significant interaction between age group and degradation, $F_{1}(1,29)=$ 5.82, $p<.05 ; F_{2}(1,108)=13.24, p<.001$. Within-group analyses showed that the degradation effect was significant for older participants, $F_{1}(1,14)=8.83, p=.01 ; F_{2}(1,54)=23.84, p<$ .001 , but not for young participants, $F_{1}(1,15)=$ $1.29 ; F_{2}(1,54)=1.87$. There was no effect of relatedness, no interaction between relatedness and degradation, and no interaction of these two variables with age group.

\section{Utterance onset latencies}

Utterance onset latency was measured from the onset of the first fixation on the left object. There was no effect of age group (means: $969 \mathrm{~ms}$ and $958 \mathrm{~ms}$ for older and young participants,

Table 2. Young and older participants' mean error rates, mean utterance latencies, and mean left-object gaze durations in Experiment 2

\begin{tabular}{|c|c|c|c|c|c|c|}
\hline \multirow[b]{2}{*}{ Condition } & \multicolumn{2}{|c|}{ Error rate } & \multicolumn{2}{|c|}{ Utterance latency } & \multicolumn{2}{|c|}{ Gaze duration left } \\
\hline & Young & Older & Young & Older & Young & Older \\
\hline \multicolumn{7}{|l|}{ Intact } \\
\hline Unrelated & 3.1 & 6.5 & $951(30)$ & $943(31)$ & $730(30)$ & $758(31)$ \\
\hline Related & 3.7 & 6.1 & $887(31)$ & $885(32)$ & $668(28)$ & $690(29)$ \\
\hline Relatedness effect & -0.6 & 0.4 & 64 & 58 & 62 & 68 \\
\hline \multicolumn{7}{|l|}{ Degraded } \\
\hline Unrelated & 4.8 & 14.3 & $1023(34)$ & $1072(35)$ & $783(41)$ & $892(43)$ \\
\hline Related & 4.1 & 11.7 & $970(32)$ & $977(33)$ & $723(34)$ & $791(35)$ \\
\hline Relatedness effect & 0.7 & 2.6 & 53 & 95 & 60 & 101 \\
\hline Degradation effect & 1.1 & 6.7 & 78 & 111 & 54 & 118 \\
\hline
\end{tabular}

Note: Error rates in percentages; gaze durations in ms. Standard errors are given in parentheses. 
respectively), but there was a significant effect of degradation, with longer latencies in the degraded condition $(1,011 \mathrm{~ms}$ vs. $917 \mathrm{~ms}) ; F_{1}(1,29)=$ 43.68; $F_{2}(1,108)=128.61$, both $p$ s $<.001$. This effect was larger in older than in young participants (111 ms vs. $78 \mathrm{~ms}$ ), but the interaction between age group and degradation was not significant. The effect of relatedness was significant, with shorter latencies in the related condition $(930 \mathrm{~ms}$ vs. $997 \mathrm{~ms}) ; F_{1}(1,29)=38.73 ; F_{2}(1$, $108)=63.80$, both $p$ s $<.001$, and was similar in size for young and older participants $(59 \mathrm{~ms}$ vs. $77 \mathrm{~ms}$ ). The relatedness effect was similar in size in the degraded and intact condition for the young participants (53 ms vs. $64 \mathrm{~ms}$ ), but was larger in the degraded condition for the older participants (95 ms vs. $58 \mathrm{~ms}$ ). This was reflected in an interaction between age group, degradation, and relatedness that approached significance, $F_{1}(1$, $29)=3.40, p<.10 ; F_{2}(1,108)=5.06, p<.05$. However, within-group analyses showed that the interaction between degradation and relatedness was not significant for either group of participants.

\section{Gaze durations for the left object}

Gaze duration for the left object was measured from the onset of the first to the offset of the last successive fixation on the object before the shift of gaze to the right object. In both groups of participants, the gaze durations were shorter than the utterance onset latencies (by, on average, $186 \mathrm{~ms}$ and $232 \mathrm{~ms}$ for older and young participants, respectively). Thus, the shift of gaze preceded the utterance onset. The effects of the experimental variables on the gaze durations mirrored those on the utterance onset latencies: There was no effect of age group (means: $783 \mathrm{~ms}$ and $726 \mathrm{~ms}$ for older and young participants); $F_{1}(1,29)=$ $1.83, p>.05 ; F_{2}(1,108)=7.84, p<.01$, but there was a significant effect of degradation, with longer gaze durations in the degraded condition $(797 \mathrm{~ms}$ vs. $712 \mathrm{~ms}) ; F_{1}(1,29)=17.59 ; F_{2}(1$, $108)=61.75$, both $p$ s $<.001$. This effect was larger in older than in young participants (118 $\mathrm{ms}$ vs. $54 \mathrm{~ms}$ ), but again the interaction was not significant.
The effect of relatedness was significant, with shorter gaze durations in the related condition (means: $718 \mathrm{~ms}$ vs. $791 \mathrm{~ms}$ ); $F_{1}(1,29)=67.25$; $F_{2}(1,108)=85.90$, both $p$ s $<.001$. Importantly, this effect was similar in size for young and older participants (61 ms vs. $84 \mathrm{~ms}) ; F_{1}(1,29)=1.73$; $F_{2}(1,108)=1.66$, both $p$ s $>.05$. As was observed on the utterance latencies, the relatedness effect was similar in size in the degraded and intact conditions for the young participants $(60 \mathrm{~ms}$ vs. $62 \mathrm{~ms}$ ), but was larger in the degraded condition for the older participants (101 ms vs. $68 \mathrm{~ms}$ ). Despite this, the interaction between age group, degradation, and relatedness was not significant. Furthermore, the interaction between degradation and relatedness was not significant for either group of participants.

In summary, in their utterance onset latencies and left-object gaze durations, the older participants did not differ significantly from the younger participants. Visual degradation prolonged and phonological relatedness reduced utterance latencies and left-object gaze durations in both age groups. This demonstrates that older speakers coordinated their speech and gaze like younger speakers: They looked at the left object until they had completed the phonological encoding of its name and then, less than $200 \mathrm{~ms}$ before utterance onset, shifted their gaze to the right object.

\section{Gaze durations for the right object}

Table 3 shows young and older participants' mean right-object gaze durations. For this measure, we obtained a significant effect of age group, $F_{1}(1,29)=15.94 ; F_{2}(1,108)=87.70$, both ps $<.001$, which was much stronger than the effect seen for the left object (effect sizes: $189 \mathrm{~ms}$ vs. $57 \mathrm{~ms}$ ). There was also a significant effect of degradation, with longer gaze durations in the degraded condition (means: $821 \mathrm{~ms}$ vs. $734 \mathrm{~ms}$ ); $F_{1}(1,29)=16.71 ; F_{2}(1,108)=63.58$, both ps $<.001$. This effect was larger for older than young participants (108 ms vs. $67 \mathrm{~ms}$ ), but the interaction was not significant.

Unexpectedly, there was a significant reversed effect of phonological relatedness to the left object, with longer gaze durations for the right 
Table 3. Young and older participants' mean right-object gaze durations in Experiment 2

\begin{tabular}{lcc}
\hline & \multicolumn{2}{c}{ Gaze duration right } \\
\cline { 2 - 3 } Condition & Young & Older \\
\hline Intact & & \\
$\quad$ Unrelated & $623(33)$ & $780(35)$ \\
Related & $677(43)$ & $856(44)$ \\
Relatedness effect & -54 & -76 \\
Degraded & & \\
Unrelated & $687(34)$ & $909(35)$ \\
Related & $746(37)$ & $943(39)$ \\
Relatedness effect & -59 & -34 \\
Degradation effect & 67 & 108 \\
\hline
\end{tabular}

Note: Gaze durations in ms. Standard errors are given in parentheses.

object in the related condition (means: $806 \mathrm{~ms}$ vs. $750 \mathrm{~ms}) ; F_{1}(1,29)=31.99 ; F_{2}(1,108)=42.68$, both $p s<.001$. This effect was similar in size for young and older participants $(57 \mathrm{~ms}$ vs. $55 \mathrm{~ms})$. It was similar in size in the degraded and intact conditions for the young participants (67 ms vs. $54 \mathrm{~ms}$ ), but was smaller in the degraded condition for the older participants $(34 \mathrm{~ms}$ vs. $76 \mathrm{~ms})$. However, neither the three-way interaction nor the interactions of degradation and relatedness within the young or the older group were significant. We return to this finding in the General Discussion.

\section{Gaze durations for the right object before and after utterance onset}

To explore further the older participants' long gaze durations for the right object, we divided the total gaze duration into time spent gazing at that object before and after utterance onset. Because we were mainly interested in the effects of age group, only this variable was entered into the analyses reported below. ${ }^{5}$ The mean gaze duration before utterance onset was shorter in older than in young participants (97 ms vs. $163 \mathrm{~ms}$ ), but this difference was only marginally significant, $F_{1}(1,29)=2.94, p<.10 ; F_{2}(1,108)=40.94, p<$ .001. In contrast, the mean gaze duration after utterance onset was significantly longer in older participants (774 ms vs. $519 \mathrm{~ms}) ; F_{1}(1,29)=$ $13.92, p=.001 ; F_{2}(1,108)=114.88, p<.001$.

While looking at and planning the name of the right object, the participants articulated the name of the left object. Thus, one explanation of older participants' prolonged gaze durations after utterance onset is that their articulation of the name of the left object was slow. The mean spoken duration of the left-object name was significantly longer in older than in young participants $(554 \mathrm{~ms}$ vs. $509 \mathrm{~ms}) ; F_{1}(1,29)=4.65 ; F_{2}(1$, $108)=6.15$, both $p$ s $<.05$. However, this $45-$ ms difference was small compared with the 255ms difference in right-object gaze durations after utterance onset. Thus, although slow speech may have contributed to the older participants' long gaze durations, it was clearly not its main cause. A more likely account is that the older participants' planning of the right-object name was slow. There is strong evidence from spontaneous speech samples that speakers use silent pausing for speech planning (Butterworth, 1975; GoldmanEisler, 1972). As an estimate of a delay in the speech planning for the right object, or of an increase in planning time, we therefore used the mean rate of silent pauses preceding its name. This rate was significantly higher in older than in young participants $(63 \%$ vs. $27 \%$ of correct trials); $F_{1}(1,29)=39.64 ; F_{2}(1,108)=151.73$, both $p$ s $<.001$.

Specific predictions can be formulated about the relationship between right-object gaze durations and the occurrence of pauses. The duration of the right-object gazes that precede utterance onset should be shorter when a pause was made than when no pause was made. This is because

\footnotetext{
${ }^{5}$ Analyses of variance with degradation and relatedness included as independent variables did not change the results. We report the results of the analyses in which these two variables were not included for reasons of consistency, since in analyses reported later, in which trial type (pause vs. no-pause) was included as an independent variable, the additional inclusion of degradation and relatedness resulted in empty cells for 3 participants. Instead of excluding the responses from these participants, we conducted the analyses on the responses averaged across the four experimental conditions.
} 
when speakers look at the right object only briefly before they begin the utterance, they will have less time before utterance onset to plan its name than when they look at it earlier. Trials with late gaze onsets may therefore be associated with higher pause rates than trials with earlier gaze onsets. Conversely, the duration of the right-object gazes that follow utterance onset should be longer when a pause was made than when no pause was made. Furthermore, the age difference in right-object gaze durations may be related to the age difference in pause rates, in which case younger and older participants should differ in their right-object gaze durations on pause trials but not on no-pause trials. To test these predictions, the analyses reported below included trial type (pause vs. no-pause) as an independent variable, in addition to age group.

As Table 4 shows, the durations of the rightobject gazes preceding and following utterance onset depended on whether participants paused before saying the right-object name. For both young and older participants, gazes that preceded utterance onset were significantly shorter on pause trials than on no-pause trials, $F_{1}(1,29)=$ $21.23 ; F_{2}(1,107)=149.77$, both $p$ s $<.001$, whereas gazes that followed utterance onset were significantly longer on pause trials, $F_{1}(1,29)=$ $140.13 ; F_{2}(1,108)=415.73$, both $p s<.001$. These results show that when participants paused before saying the right-object name, they looked at the right object less time before beginning to speak and more time after beginning to speak than when they did not pause. As mentioned earlier, older participants paused on most trials. Thus, the finding that right-object gaze durations after utterance onset were prolonged on pause trials suggests that their long gazes at the right object were due to their frequent pauses. However, gazes at the right object after utterance onset were longer in older than in young participants not only on pause trials (by $124 \mathrm{~ms}$ ) but also on no-pause trials (by $167 \mathrm{~ms}$ ). Thus, the older participants' long right-object gaze durations cannot be due to their frequent pauses alone.

Participants in the present experiment could have gained time in their planning of the rightobject name not only by pausing before saying the name, but also by lengthening the duration of the left-object name. As Table 4 shows, older participants showed a trade-off between the spoken duration of the left-object names and the occurrence of pauses: The mean duration of the left-object name was longer when they did not pause than when they paused. In contrast, in young participants, the mean duration of the left-object name was similar for pause and nopause trials. This interaction between age group and trial type was significant, $F_{1}(1,29)=12.08$, $p<.01 ; F_{2}(1,108)=17.27, p<.001$. These results show that when word lengthening is considered a way of compensating for delays in speech planning, in addition to silent pausing, older participants' long gaze durations for the right object can be associated with slow or delayed speech planning.

In summary, the right-object gaze durations after utterance onset were longer for the older

Table 4. Young and older participants' mean pause rates, mean durations of the left-object name for pause and no-pause trials, and mean right-object gaze durations before and after utterance onset for pause and no-pause trials in Experiment 2

\begin{tabular}{|c|c|c|c|c|c|c|c|}
\hline & \multirow[b]{3}{*}{ Pause rate } & & & \multicolumn{4}{|c|}{ Gaze duration right } \\
\hline & & \multicolumn{2}{|c|}{ Articulatory duration left } & \multicolumn{2}{|c|}{ Before utterance onset } & \multicolumn{2}{|c|}{ After utterance onset } \\
\hline & & Pause & No pause & Pause & No pause & Pause & No pause \\
\hline Young & 27 & $519(15)$ & $512(14)$ & $140(27)$ & $185(26)$ & $762(55)$ & $405(37)$ \\
\hline Older & 63 & $531(16)$ & $591(15)$ & $94(28)$ & $126(27)$ & $886(57)$ & $572(35)$ \\
\hline
\end{tabular}

Note: Pause rates in percentages; mean durations in ms. Standard errors are given in parentheses. 
than the young participants. This age difference co-occurred with an age difference in speech fluency: The older participants articulated the name of the left object more slowly than young participants and paused more often before saying the name of the right object. These age differences contrasted with the small age differences in utterance onset latencies and left-object gaze durations.

\section{GENERAL DISCUSSION}

The present experiments showed that both younger and older speakers plan their speech very sequentially. This conclusion is based on two results. First, in Experiment 1, in which participants named single objects that were visually intact or degraded while hearing distractor words that were phonologically related or unrelated to the objects, visual degradation prolonged and phonological relatedness reduced the naming latencies. These effects were additive, suggesting that younger and older speakers identify the object before retrieving the form of its name. Second, in Experiment 2, in which participants named object triplets, the young participants showed the expected effects of visual degradation and phonological relatedness on the utterance latencies and left-object gaze durations, demonstrating that they looked at the left object until they had planned its name to a phonological level and then shifted their gaze to the right object (see also Meyer et al., 2007). The older participants too showed these effects, demonstrating that both younger and older speakers plan the names of successive objects sequentially, completing most of the planning of the first name before beginning to plan the next.

We formulated two hypotheses about how speakers plan the names of successive objects: the fluency maintenance hypothesis and the minimal load hypothesis. The fluency maintenance hypothesis predicts that speakers shift their gaze to the second object early relative to the onset of the utterance to increase the time available before utterance onset to plan its name, thus increasing the likelihood that the fluency of the utterance is maintained. In contrast, the minimal load hypothesis predicts that speakers shift their gaze late to delay processing of the second object until processing of the first is almost complete, thus minimizing the processing load. The present study showed that both younger and older speakers shift their gaze slightly before utterance onset. The older participants shifted their gaze even later than the young participants (on average $186 \mathrm{~ms}$ and $232 \mathrm{~ms}$ before utterance onset, respectively). Although this difference was only marginally significant, it suggests that older speakers might have a stronger preference than younger speakers for minimizing their processing load. In our experiment, the instructions, which emphasized that the utterances should be initiated promptly, and which did not mention fluency, may have encouraged the speakers to use a sequential planning strategy. Further research might determine whether speakers adopt a different planning strategy when fluency is important (e.g., Ferreira \& Swets, 2002; Griffin, 2003; Griffin \& Spieler, 2000; see also Damian \& Dumay, 2007).

The finding that visual degradation and phonological relatedness affected the young participants' left-object gaze durations replicates earlier findings by Meyer et al. (1998), who also presented visually intact and degraded pictures, and by Meyer and van der Meulen (2000), who also presented phonologically related and unrelated distractors. Thus, the present results support the view that young speakers naming several objects look at each object until they have identified it and ended the phonological encoding of its name. Only then do they shift their gaze to the next object. The age similarity in the phonological relatedness effect on left-object gaze durations is consistent with the results of Spieler and Griffin (2006), who found effects of the frequency of the left-object name on gaze durations for the object in both younger and older speakers. Word frequency effects probably arise at the morphological or an earlier planning level (e.g., Alario, Costa, \& Caramazza, 2002; Caramazza, Costa, Miozzo, \& Bi, 2001; Jescheniak \& Levelt, 1994; Jescheniak, Meyer, \& Levelt, 2003a). Our results take those 
of Spieler and Griffin one step further because they demonstrate that the similarity in the coordination of eye gaze and speech between young and older speakers extends to the level of phonological encoding.

An additional effect of phonological relatedness to the left object was the reversed effect on the gaze durations for the right object: Processing of the right object was slower when the distractor was phonologically related to the left object than when it was unrelated. We have obtained the same pattern in a companion study (Mortensen, 2006). Its origin needs to be further investigated. Our current hypothesis is that the phonologically related distractor words had two effects: Relative to the unrelated distractors, they facilitated the phonological encoding of the name of the left object and thereby reduced the utterance onset latencies and left-object gaze durations, but they also interfered with the speakers' self-monitoring processes. According to all current theories of speech production, speakers continuously monitor their own speech by scrutinizing their speech plan (the phonological or phonetic representation) or/and their overt speech (e.g., Blackmer \& Mitton, 1991; Hartsuiker, Kolk, \& Martensen, 2005; Postma \& Kolk, 1993; Slevc \& Ferreira, 2006). In a multiple-object naming task, speakers typically move their eyes from the first to the second object as soon as they have retrieved the phonological form of the first object name. This means that they tend to be looking at the second object during the articulation and monitoring of the first object name. If monitoring is difficult, the concurrent processing of the second object may be slowed down, which will manifest itself in longer gaze durations to the second object than in a situation where monitoring is easier. The observed effects of the distractors on the duration of the gazes to the right object can be explained by assuming that self-monitoring is more difficult in the presence of a related than of an unrelated distractor. The related distractor may, for instance, make it more difficult for the speaker than an unrelated distractor to identify the prepared or spoken phonological form or to match it to the intended form. Independent evidence supporting this hypothesis comes from recent studies by Slevc and Ferreira (2006) and Cook and Meyer (2007).

The older participants were significantly slower than the young participants to begin to speak in Experiment 1 but not in Experiment 2. ${ }^{6}$ In the latter experiment, they were only significantly slower after utterance onset. Compared with a single-object naming task, a task requiring the naming of three objects must be more demanding as the amount of processing is tripled. Therefore, one might have expected a larger age difference in utterance onset latencies in Experiment 2 than in Experiment 1. One explanation is that the young and older participants reacted differently to the limited picture exposure time in the two experiments. In the single-object naming experiment, where the pictures were only shown for $1,500 \mathrm{~ms}$, both groups presumably felt that they had to respond as fast as possible. In Experiment 2 , the pictures were shown for much longer $(4,000 \mathrm{~ms})$. The young participants might therefore have felt that they could respond at a leisurely pace, whereas the older participants might still have felt to be under time pressure. The feeling of time pressure in Experiment 1 but not in Experiment 2 could have contributed to the difference between the young participants' utterance onset latencies in the two experiments (means: $767 \mathrm{~ms}$ vs. $958 \mathrm{~ms}$, respectively). In contrast, the older participants might have felt a time pressure in both experiments, and therefore the difference between their utterance onset latencies in the two experiments was smaller (858 ms vs. $969 \mathrm{~ms})$. Furthermore, older

\footnotetext{
${ }^{6} \mathrm{We}$ did not obtain information about years of education from the participants of Experiment 1 . Therefore, we cannot rule out that the older participants of this experiment had fewer years of education than the young participants, and that this contributed to their longer speech onset latencies. However, they were recruited from the same participant pool as were the participants of Experiment 2 (who had stayed in education for longer than the undergraduates we tested), and we would certainly not expect a large difference in educational level.
} 
participants made significantly more errors than young participants in Experiment 2 (but not in Experiment 1). The finding that the older participants' utterance latencies were not longer might be due to this speed-accuracy trade-off. The observation that the young and older participants did not differ significantly in the time they spent looking at the left object (means: $726 \mathrm{~ms}$ vs. $783 \mathrm{~ms}$, respectively) can also be explained within this time pressure account.

In Experiment 2, both young and older participants planned their utterances sequentially, as evidenced by their late shifts of gaze to the right object relative to utterance onset. They differed, however, in how this sequentiality affected their utterances. First, the older participants were more disfluent: They produced more errors when naming the right object (i.e., incorrect names and hesitations) and paused more often before producing its name. Second, they articulated the name of the left object more slowly. Evidence that this age difference is related to how far the right-object name was planned at utterance onset comes from the trade-off that older participants showed between the spoken duration of the leftobject name and the occurrence of a pause before the right-object name: When they produced the two names without an intervening pause, they extended the duration of the left-object name (by about $60 \mathrm{~ms}$ ). Finally, the older participants looked longer than the young participants at the right object after utterance onset. All participants had longer gaze durations for the right object after utterance onset when they paused before articulating its name than when they did not pause, but the rate of trials on which a pause occurred was higher in older participants. These results suggest that older participants looked longer at the right object because they needed more time after utterance onset to plan its name and often more time than available, hence the many pauses.

The co-occurrence of long gaze durations for the right object and pauses before its name in all participants confirms that eye gaze is tightly linked to the planning and fluency of speech (e.g., Griffin \& Bock, 2000). This link is also confirmed by the finding that the onset of gaze affected utterance fluency: When participants looked at the right object late relative to utterance onset, their utterances were less fluent (i.e., they paused more often) than when they looked earlier. This suggests that disfluent speech can be due to a delay in gazing at the object and thus in planning its name. Compelling evidence for a relationship between the onset of gaze and utterance fluency comes from a study by BrownSchmidt and Tanenhaus (2006). When young participants looked at an object that differed from the target object in size (e.g., a large vs. small horse) early relative to the onset of the utterance, they produced fluent utterances in the form of a noun phrase with a prenominal adjective ("the small horse"). When they looked at the contrast object later, they still referred to the size of the target object with a prenominal adjective, but their utterances were no longer fluent ("thee uh small horse"). Finally, when they looked at the contrast object after utterance onset, they referred to size using a postnoun repair phrase ("the horse ... uh the small one"). These results suggest that the onset of gazing at an object affects not only utterance fluency but also utterance form.

The present results suggest that this link between eye gaze and speech is unaffected by ageing. What is affected by ageing is the duration of the gazes to an object that is named after another object has been named and the frequency of the pauses preceding this object's name. Age differences in the duration of gazes at objects and in utterance fluency were also observed by Spieler and Griffin (2006). They found that age differences in mean gaze durations were larger for noninitial objects after utterance onset than for initial objects (318 ms vs. $143 \mathrm{~ms}$ ). Young participants were disfluent when producing the names of the noninitial objects on $21 \%$ of the trials, whereas older participants were disfluent on a significantly higher $35 \%$ of the trials. Older participants were particularly disfluent when naming noninitial objects with low name agreement and low name frequency, suggesting that the disfluencies were related to the retrieval of the names. However, there was no age difference in the effects of 
name agreement and name frequency on the gaze durations for noninitial objects. Therefore, difficult name retrieval cannot alone explain the age differences in gaze durations observed in their study.

One explanation of the age differences in the gaze durations for the right object in the present study is that the older participants had difficulty inhibiting specific representations of the left object, such as its visual form, meaning, or name, when beginning to process the right object. If this was the case, the left object may have interfered with their processing of the right object more than in the young participants. However, studies using the semantic blocking paradigm (i.e., objects presented repeatedly in sets of semantically related or unrelated objects) show blocking effects on naming latencies of similar sizes in younger (Belke, Meyer, \& Damian, 2005) and older (Schnur, Schwartz, Brecher, \& Hodgson, 2006) speakers. Using this paradigm with both younger and older speakers, Belke and Meyer (in press) observed a slightly larger effect of semantic blocking on the gaze durations and pause rates of the older than the young participants, but the observed effects on the utterance onset latencies and articulatory durations were similar for the two age groups. Semantic blocking maximizes the possibility of interference between objects. Despite this, there was either no or only a small increase in the size of the effect in older speakers. Thus, it seems unlikely that interference is responsible for the age differences in the present study, in which triplets of semantically unrelated objects were used. Furthermore, we found no evidence in the older participants' gaze pattern for interference from the left object. They had as few returns of gaze to the left object as had the young participants (on $3.5 \%$ vs. $3.7 \%$ of all trials, respectively).

Instead, the older participants' long rightobject gaze durations could be due to a decline in visual attention, either in capacity (Maylor \& Lavie, 1998; McCarley, Mounts, \& Kramer, 2004) or in widening and shifting focus (e.g., Hartley, Kieley, \& McKenzie, 1992; Kosslyn, Brown, \& Dror, 1999). Such a decline could have prevented them from attending to the right object while gazing at the left, thus delaying their processing of the right object until after they gazed at it. In a companion study (Mortensen, 2006), we tested for age differences in the extrafoveal processing of objects using the variant of the boundary-change paradigm introduced by Morgan and Meyer (2005). The older speakers were as able as the young speakers to process objects extrafoveally, even when the processing load for the fixated object was increased by the presentation of auditory distractor words. Therefore, reduced extrafoveal processing of objects is unlikely to be responsible for the older speakers' long gaze durations in the present study.

A more likely account is that the older participants' long gaze durations and their disfluent speech were due to slow speech planning. According to this account, the older speakers adopted the same sequential planning strategy as did the younger speakers: They planned the name of the left object to the level of phonological encoding and then shifted their gaze and began to plan the name of the right object. For the older speakers, this sequential planning of the names led to disfluent speech because the time available during the articulatory planning and articulation of the first name was too short to complete the planning of the second name.

One finding that seems problematic for the slow speech planning account is that the age difference in right-object gaze durations remained when the participants did not pause before its name. If the older participants' long right-object gaze durations were due to slow planning of the object's name, they should co-occur with other indicators of planning difficulty, such as pauses. However, on these no-pause trials, older participants extended the duration of the left-object name, which can also indicate planning difficulty. Apparently, older speakers are flexible in the strategy that they use to gain time for speech planning: They either pause in their speech or speak more slowly (for evidence for a similar flexibility in young speakers, see Ferreira \& Swets, 2002). 
We found an effect of age group on the naming latencies and gaze durations for the right objects, but not on the utterance onset latencies and the gaze durations for the left objects. If older speakers are slower to plan their speech than younger speakers, one might have expected an effect of age on the planning of the names of both objects. The effect of age was confined to the naming of the right object, possibly because the second word of the utterances was more difficult to plan than the first word. A speaker begins to plan a second word while completing the final planning processes for the first word, while articulating that word, and while monitoring it once it has been articulated. In combination, these processes pertaining to the left object may have slowed down the older participants' planning of the name of the right object.

Alternatively, as mentioned earlier, the older participants might have felt more under time pressure than the young participants when performing the multiple-object naming task. Such a difference could have eliminated any differences between the groups in their utterance onset latencies and their gaze durations for the left objects. This account predicts that when young and older speakers do not differ in their feeling of time pressure, older speakers should be slower than young speakers to plan the words of multiword utterances, regardless of the position of the word in the utterance.

In conclusion, the present results show that both younger and older speakers plan simple descriptive utterances sequentially. Despite this, younger speakers produce fluent utterances, whereas older speakers are less fluent utterance internally, with more hesitations, more silent pauses, and longer speech durations. Thus, replicating earlier studies we found that the speech of older persons was slower and more hesitant than the speech of younger persons, but we can now exclude that this difference is due to fundamentally different ways of planning utterances.

Original manuscript received 13 November 2006 Accepted revision received 15 May 2007 First published online 9 August 2007

\section{REFERENCES}

Alario, F. X., Costa, A., \& Caramazza, A. (2002). Frequency effects in noun phrase production: Implications for models of lexical access. Language and Cognitive Processes, 17, 299-319.

Belke, E., \& Meyer, A. S. (in press). Single and multiple object naming in healthy ageing. Language and Cognitive Processes.

Belke, E., Meyer, A. S., \& Damian, M. F. (2005). Refractory effects in picture naming as assessed in a semantic blocking paradigm. Quarterly Journal of Experimental Psychology, 58A, 667-692.

Biederman, I. (1987). Recognition-by-components: A theory of human image understanding. Psychological Review, 94, 115-147.

Biederman, I., \& Cooper, E. E. (1991). Priming contour-deleted images: Evidence for intermediate representations in visual object recognition. Cognitive Psychology, 23, 393-419.

Blackmer, E. R., \& Mitton, J. L. (1991). Theories of monitoring and the timing of repairs in spontaneous speech. Cognition, 39, 173-194.

Bortfeld, H., Leon, S. D., Bloom, J. E., Schober, M. F., \& Brennan, S. E. (2001). Disfluency rates in conversation: Effects of age, relationship, topic, role, and gender. Language and Speech, 44, 123-147.

Brown-Schmidt, S., \& Tanenhaus, M. K. (2006). Watching the eyes when talking about size: An investigation of message formulation and utterance planning. Journal of Memory and Language, 54, 592-609.

Butterworth, B. (1975). Hesitation and semantic planning in speech. Journal of Psycholinguistic Research, $1,75-78$.

Caramazza, A., Costa, A., Miozzo, M., \& Bi, Y. (2001). The specific-word frequency effect: Implications for the representation of homophones in speech production. Journal of Experimental Psychology: Learning, Memory, and Cognition, 27, 1430-1450.

Cook, A. E., \& Meyer, A. S. (2007). Capacity demands of word production: New evidence from dual-task experiments. Manuscript submitted for publication.

Cooper, P. V. (1990). Discourse production and normal aging: Performance on oral picture description tasks. Journal of Gerontology: Psychological Sciences, 45, P210-P214.

Costa, A., \& Caramazza, A. (2002). The production of noun phrases in English and Spanish: Implications for the scope of phonological encoding in speech production. Journal of Memory and Language, 46, 178-198. 
Damian, M. F., \& Dumay, N. (2007). Time pressure and phonological advance planning in spoken production. Journal of Memory and Language, 57, 195-209.

Damian, M. F., \& Martin, R. C. (1999). Semantic and phonological codes interact in single word production. Journal of Experimental Psychology: Learning, Memory, and Cognition, 25, 345-361.

Danziger, W. L., \& Salthouse, T. A. (1978). Age and the perception of incomplete figures. Experimental Ageing Research, 4, 67-80.

Davidson, D. J., Zacks, R. T., \& Ferreira, F. (2003). Age preservation of the syntactic processor in production. Journal of Psycholinguistic Research, 32, 541-566.

Dell, G. S. (1986). A spreading-activation theory of retrieval in sentence production. Psychological Review, 93, 283-321.

Ferreira, F., \& Swets, B. (2002). How incremental is language production? Evidence from the production of utterances requiring the computation of arithmetic sums. Journal of Memory and Language, 46, 57-84.

Frazer, L., \& Hoyer, W. J. (1992). Object recognition by component features-are there age differences? Experimental Aging Research, 18, 9-14.

Garrett, M. F. (1975). The analysis of sentence production. In G. Bower (Ed.), Psychology of learning and motivation (Vol. 9, pp. 133-177). New York: Academic Press.

Goldman-Eisler, F. (1972). Pauses, clauses, sentences. Language and Speech, 15, 103-113.

Griffin, Z. M. (2001). Gaze durations during speech reflect word selection and phonological encoding. Cognition, 82, B1-B14.

Griffin, Z. M. (2003). A reversed word length effect in coordinating the preparation and articulation of words in speaking. Psychonomic Bulletin E Review, 10, 603-609.

Griffin, Z. M. (2004). Why look? Reasons for eye movements related to language production. In J. M. Henderson \& F. Ferreira (Eds.), The interface of language, vision, and action: What we can learn from free-viewing eye tracking (pp. 213-247). New York: Psychology Press.

Griffin, Z. M., \& Bock, K. (2000). What the eyes say about speaking. Psychological Science, 11, 274-279.

Griffin, Z. M., \& Oppenheimer, D. M. (2006). Speakers gaze at objects while preparing intentionally inaccurate labels for them. Journal of Experimental Psychology: Learning, Memory, and Cognition, 32, 943-948.
Griffin, Z. M., \& Spieler, D. H. (2000, November). Speech planning in younger and older adults. Poster presented at the 41st Annual Meeting of the Psychonomic Society, New Orleans, LA, USA.

Griffin, Z. M., \& Spieler, D. H. (2006). Observing the what and when of language production for different age groups by monitoring speakers' eye movements. Brain and Language, 99, 272-288.

Hartley, A. A., Kieley, J. M., \& McKenzie, C. R. M. (1992). Allocation of visual attention in young and older adults. Perception and Psychophysics, 52, 175-185.

Hartsuiker, R. J., Kolk, H. H. J., \& Martensen, H. (2005). The division of labor between internal and external speech monitoring. In R. J. Hartsuiker, Y. Bastiaanse, A. Postma, \& F. Wijnen (Eds.), Phonological encoding and monitoring in normal and pathological speech (pp. 187-205). Hove, UK: Psychology Press.

Irwin, D. E. (2004). Fixation location and fixation duration as indices of cognitive processes. In J. M. Henderson \& F. Ferreira (Eds.), The interface of language, vision, and action: What we can learn from free-viewing eye tracking (pp. 105-134). New York: Psychology Press.

Jescheniak, J. D., \& Levelt, W. J. M. (1994). Word frequency effects in speech production: Retrieval of syntactic information and of phonological form. Journal of Experimental Psychology: Learning, Memory, and Cognition, 20, 824-843.

Jescheniak, J. D., Meyer, A. S., \& Levelt, W. J. M. (2003a). Specific-word frequency is not all that counts in speech production. Some comments on Caramazza et al. (2001) and new experimental data. Journal of Experimental Psychology: Learning, Memory, and Cognition, 29, 432-438.

Jescheniak, J. D., Schriefers, H., \& Hantsch, A. (2003b). Utterance format affects phonological priming in the picture-word task: Implications for models of phonological coding in speech production. Journal of Experimental Psychology: Human Perception and Performance, 29, 441-454.

Kosslyn, S. M., Brown, H. D., \& Dror, I. E. (1999). Ageing and the scope of visual attention. Gerontology, 45, 102-109.

Levelt, W. J. M. (1989). Speaking: From intention to articulation. Cambridge, MA: MIT Press.

Levelt, W. J. M., \& Meyer, A. S. (2000). Word for word: Multiple lexical access in speech production. European Journal of Cognitive Psychology, 12, 433-452. 
Levelt, W. J. M., Roelofs, A., \& Meyer, A. S. (1999). A theory of lexical access in speech production. Behavioral and Brain Sciences, 22, 1-38.

Martin, R. C., Miller, M., \& Vu, H. (2004). Lexicalsemantic retention and speech production: Further evidence from normal and brain-damaged participants for a phrasal scope of planning. Cognitive Neuropsychology, 21, 625-644.

Max Planck Institute for Psycholinguistics (2000). The Nijmegen Experiment Setup (NESU) [Computer software]. Nijmegen, The Netherlands: Max Planck Institute for Psycholinguistics.

Maylor, E. A., \& Lavie, N. (1998). The influence of perceptual load on age differences in selective attention. Psychology and Aging, 13, 563-573.

McCarley, J. S., Mounts, J. R. W., \& Kramer, A. F. (2004). Age-related differences in localized attentional interference. Psychology and Aging, 19, 203210.

Meyer, A. S. (1996). Lexical access in phrase and sentence production. Journal of Memory and Language, 35, 477-496.

Meyer, A. S. (1997). Conceptual influences on grammatical planning units. Language and Cognitive Processes, 12, 859-863.

Meyer, A. S., Belke, E., Häcker, C., \& Mortensen, L. (2007). Use of word length information in utterance planning. Journal of Memory and Language, 57, 210-231.

Meyer, A. S., \& Lethaus, F. (2004). The use of eye tracking in studies of sentence generation. In J. M. Henderson \& F. Ferreira (Eds.), The interface of language, vision, and action: What we can learn from free-viewing eye tracking (pp. 191-211). New York: Psychology Press.

Meyer, A. S., Roelofs, A., \& Levelt, W. J. M. (2003). Word length effects in picture naming: The role of a response criterion. Journal of Memory and Language, 47, 131-147.

Meyer, A. S., \& Schriefers, H. (1991). Phonological facilitation in picture-word interference experiments: Effects of stimulus onset asynchrony and types of interfering stimuli. Journal of Experimental Psychology: Learning, Memory, and Cognition, 17, 1146-1160.

Meyer, A. S., Sleiderink, A. M., \& Levelt, W. J. M. (1998). Viewing and naming objects: Eye movements during noun phrase production. Cognition, 66, B25-B33.

Meyer, A. S., \& van der Meulen, F. F. (2000). Phonological priming effects on speech onset latencies and viewing times in object naming. Psychonomic Bulletin E Review, 7, 314-319.

Miozzo, M., \& Caramazza, A. (1999). The selection of determiners in noun phrase production. Journal of Experimental Psychology: Learning, Memory, and Cognition, 25, 907-922.

Morgan, J. L., \& Meyer, A. S. (2005). Processing of extrafoveal objects during multiple object naming. Journal of Experimental Psychology: Learning, Memory, and Cognition, 31, 428-442.

Mortensen, L. (2006). The interface between vision and language in normal ageing and in neurological patients. Unpublished doctoral dissertation, University of Birmingham, UK.

Mortensen, L., Meyer, A. S., \& Humphreys, G. W. (2006). Age-related effects on speech production: A review. Language and Cognitive Processes, 21, 238-290.

Postma, A., \& Kolk, H. H. J. (1993). The covert repair hypothesis: Prearticulatory repair processes in normal and stuttered disfluencies. Journal of Speech and Hearing Research, 35, 472-487.

Salthouse, T. A., \& Prill, K. A. (1988). Effects of aging on perceptual closure. American Journal of Psychology, 101, 217-238.

Schnur, T. T., Schwartz, M. F., Brecher, A., \& Hodgson, C. (2006). Semantic interference during blocked-cyclic naming: Evidence from aphasia. Journal of Memory and Language, 54, 199-227.

Schriefers, H. (1992). Lexical access in the production of noun phrases. Cognition, 45, 33-54.

Schriefers, H. (1993). Syntactic processes in the production of noun phrases. Journal of Experimental Psychology: Learning, Memory, and Cognition, 19, 841-850.

Schriefers, H., \& Teruel, E. (1999). Phonological facilitation in the production of two-word utterances. European Journal of Cognitive Psychology, 11, 17-50.

Slevc, L. R., \& Ferreira, V. S. (2006), Halting in single word production: A test of the perceptual loop theory of speech monitoring. Journal of Memory and Language, 54, 515-540.

Smith, M. C., \& Wheeldon, L. R. (1999). High level processing in spoken sentence production. Cognition, 73, 205-246.

Smith, M. C., \& Wheeldon, L. R. (2004). Horizontal information flow in spoken sentence production. Journal of Experimental Psychology: Learning, Memory, and Cognition, 30, 675-686.

Spieler, D. H., \& Griffin, Z. M. (2006). The influence of age on the time course of word preparation in 
multiword utterances. Language and Cognitive Processes, 21, 291-321.

Taylor, J. K., \& Burke, D. M. (2002). Asymmetric ageing effects on semantic and phonological processes: Naming in the picture-word interference task. Psychology and Aging, 17, 662-676.

van der Meulen, F. F., Meyer, A. S., \& Levelt, W. J. M. (2001). Eye movements during the production of nouns and pronouns. Memory and Cognition, 29, 512-521.
Wheeldon, L. R., \& Lahiri, A. (1997). Prosodic units in speech production. Journal of Memory and Language, 37, 356-381.

Whitfield, K. E., \& Elias, J. W. (1992). Age cohort differences in the ability to perform perceptual closure on degraded pictures. Experimental Aging Research, 18, 67-73.

Wilshire, C. E., \& Saffran, E. M. (2005). Contrasting effects of phonological priming in aphasic word production. Cognition, 95, 31-71.

\section{APPENDIX}

\section{Materials used in Experiments 1 and 2}

Target (left) objects/related distractors: anchor/vicar, arm/farm, bag/rag, banana/piranha, bear/scare, bell/spell, bone/phone, book/look, broom/zoom, brush/crush, cactus/tortoise, camel/enamel, can/flan, castle/whistle, cheese/breeze, church/birch, cook/hook, cross/boss, curtain/baton, dress/ stress, factory/diary, finger/singer, flag/lag, flute/suit, fork/ pork, guitar/cigar, gun/fun, hammer/grammar, hand/band, harp/sharp, hat/bat, kettle/nettle, lemon/sermon, mask/task, moon/dune, onion/champion, organ/wagon, pig/gig, plane/ strain, rocket/pocket, saw/law, scooter/hooter, seal/deal, ship/clip, snail/mail, sock/wok, square/pear, swing/king, table/cable, tent/rent, top/cop, tree/knee, trousers/scissors, vase/mars, violin/zeppelin.
Right objects: ball, cake, wheel, key, iron, giraffe, tire, toaster, nun, palm, watch, lorry, ladder, toilet, pencil, knife, snake, lamp, plant, rake, plug, leaf, cigarette, dog, robot, ring, shuttle, kite, rabbit, well, toe, statue, arch, swan, saddle, sword, pot, ruler, trumpet, desk, bow, door, eye, umbrella, camera, penguin, monkey, pan, sheep, spider, belt, star, bed, stool, boot.

Bottom objects: bowl, bread, bus, cap, car, cat, chair, clock, clown, coat, comb, crown, cup, doll, drum, ear, elephant, feather, fence, foot, fox, frog, glass, globe, glove, hair, heart, horse, house, jug, leg, lock, nose, owl, pen, piano, pie, pin, pipe, pump, purse, rope, shirt, shoe, skirt, sled, slide, spoon, stamp, sun, tap, tie, waiter, web, whale. 